\title{
Sensitivity Analysis of Model Parameters for Water Quality Simulation
}

\author{
Nireshini Naidoo, Muthukrishnavellaisamy Kumarasamy*
}

Civil Engineering Programme, School of Engineering, University of KwaZulu-Natal, Durban, South Africa

Received: 6 January 2016

Accepted: 21 February 2016

\begin{abstract}
The Hybrid Cells in Series model consists of a plug flow cell - first and second well-mixed cells in series that represent advective-dispersive transport pollutants in river reaches. The key model parameters are the cell residence times $\left(\alpha, T_{1}\right.$, and $\left.T_{2}\right)$, which require parameter optimization to calibrate the model and to identify the sensitivity of model parameters. The least square error optimization method was used to determine the model parameters. Tracer test data was adopted to evaluate the sensitivity of the hybrid model response to a unit impulse input of a conservative pollutant. Factor perturbation was applied to determine the parameter with the greatest influence on hybrid unit output. The $\mathrm{n}^{\text {th }}$ hybrid unit output was generated using a convolution technique and compared to the observed output from available field data. Traditionally, the longitudinal dispersion coefficient $\left(\mathrm{D}_{\mathrm{L}}\right)$ of a particular waterway is calculated according to the physical flow and channel properties. These properties are hardly regular, and the investigation into the use of moments to determine $\mathrm{D}_{\mathrm{L}}$ helps to eliminate uncertainties for future hydraulic modelling ventures. Parameters $\alpha$ and $\mathrm{T}_{2}$ are more sensitive, needing accurate estimation to correctly reproduce concentration-time profile, and to simulate river water quality.
\end{abstract}

Keywords: HCIS model, pollutant transport model, parameter estimation, parameter sensitivity

\section{Introduction}

Water pollution is generally caused by increases in industrial, mining, agricultural, and domestic activities unless certain precautions are taken [1]. Freshwater sources in many countries are being challenged and their capacity to handle the waste from human activity is reaching its limits. The growing needs to control and monitor pollution are about the investigation of the responses of waterways to pollutants and mitigating them

*e-mail: kumarasamy@ukzn.ac.za
[2]. Water quality modelling generally allows investigators to develop a more in-depth understanding of the fate and transport of pollutants in river reaches. The relationships between pollution characteristics, sources, and the effects of these pollutants on water quality can be dealt with mathematically [3]. Water quality models have been widely used for creating the scientific basis for environmental management decisions by providing a predictive link between ecosystem response and management actions [47]. The well-known advection dispersion equation (ADE) model has limitations to apply for natural streams due to the non-uniform flow conditions and difficulty in determining the parameter longitudinal dispersion coefficient, $\mathrm{D}_{\mathrm{L}}[8-$ 11]. There are a wide range of theoretical and experimental methods to estimate $\mathrm{D}_{\mathrm{L}}$. The variation in available methods 
gives rise to the uncertainty in applying a particular water quality model, since a value of river flow velocity, $u$, and longitudinal dispersion coefficient, $\mathrm{D}_{\mathrm{L}}$, are required before attempting to simulate the transport of the tracer cloud. As an alternative to the ADE model, various models - namely the cells in series (CIS), aggregated dead zone (ADZ), transient storage (TS), variable residence time (VART), and hybrid cells in series (HCIS) models - have been developed and used [8, 10, 12-16]. The CIS model does not simulate advection adequately and the difficulty with the ADZ model is in determining model order and model parameters [8]. The HCIS model has apparently overcome the limitations of the ADE, CIS, and ADZ models, as the simulation of contaminant transport under steady flow conditions closely resembles the ADE model $[8,14]$. The HCIS model has three time parameters $\left(\alpha, T_{1}\right.$, and $\left.T_{2}\right)$ that are the residence times for the plug flow and the two wellmixed cells, respectively (i.e., the volume of respective cells over flow rate). The desired skewed concentrationtime profile using the HCIS model can be obtained when the Peclet number $\left(\mathrm{P}_{\mathrm{e}}=\mathrm{u} \Delta \mathrm{x} / \mathrm{D}_{\mathrm{L}}\right)$ is larger than or equal to $4[8,14]$; in other words, when the hybrid unit size $(\Delta x)$ of the HCIS Model is greater than or equal to $4 \mathrm{D}_{\mathrm{L}} / \mathrm{u}$., Ghosh et al. [14] suggest empirical relationships to determine the HCIS model parameters as a function of $u$ and $D_{L}$. As the value of $D_{L}$ is highly variable, the aim of this study is to attempt to eliminate any uncertainty that arises from the use of the $u$ and $D_{L}$ in determining the HCIS model parameters. A sensitivity analysis was previously carried out by [17] using synthetic data, but it is necessary to test the sensitivity of the model response in comparison to field measurements of contaminant concentrations. Thus, our study also aims to analyse the sensitivity of the above model parameters.

\section{Methodology}

\section{Model Description and Parameter Optimization}

A river reach is conceptualized to have a series of hybrid units and each hybrid unit consists of a plug flow cell and first and second well-mixed cells all connected in series. Solving mass balance equation for one process unit for step input perturbation, Ghosh et al. [14] has derived step response of the HCIS model. Time derivative of the step response is an impulse response as given in Eq. (1) $[8,14]$ :

$$
\frac{d\left(K_{H C I S}\right)}{d t}=k_{H C I S}=\frac{C_{R} U(t-\alpha)}{\left(T_{1}-T_{2}\right)}\left\{e^{-\left(\frac{t-\alpha}{T_{1}}\right)}-e^{-\left(\frac{t-\alpha}{T_{2}}\right)}\right\}
$$

...where $K_{\text {HCIS }}$ and $k_{H C I S}$ are step and impulse responses of the HCIS model, respectively, $C_{R}$ is input pollutant concentration, $t$ is time, and $U($.$) is unit step function.$
The principle of parameter estimation is based on solving for the unknown model time parameters from a measured response to a particular input concentration. An impulse response function is a C-t profile, which has distinctive characteristics such as peak concentration, time to peak, and nature of the rising and falling limbs. This C-t profile can be used to determine the HCIS model parameters by the least square optimization method. The method of least squares by Marquardt algorithm provides a procedure to reduce the error or difference between the observed C-t profile and the same simulated by the model with initial guesses of the model parameters. The sum of square error between observed and calculated C-t profiles is given in Eq. (2) as:

$$
E=\sum_{i=1}^{n}\left[k_{\text {obs }}(i \Delta t)-k_{H C I S}\left(\alpha^{\prime}+\Delta \alpha ; T_{1}^{\prime}+\Delta T_{1} ; T_{2}^{\prime}+\Delta T_{2}, i \Delta t\right)\right]^{2}
$$

...where $E$ is sum of square error; $k_{o b s}$ is observed concentration time profile; $\alpha, \mathrm{T}_{1}$, , and $\mathrm{T}_{2}$, are initial guesses of time parameters of the model; $\Delta \alpha, \Delta \mathrm{T}_{1}$, and $\Delta \mathrm{T}_{2}$ are differences in the values of the model parameters between iterations; $i$ is integer; and $\Delta \mathrm{t}$ is time step.

Applying Taylor's series of expansion and neglecting higher order terms, the partial derivatives of Eq. (2) with respect to each model parameter are equated to zero. Ultimately the solution for the HCIS model parameters was derived as an inverse problem by matrix methods and the values of $\Delta \alpha, \Delta T_{1}$, and $\Delta T_{2}$ are determined. After each iteration, model parameters were updated by $\alpha=\alpha^{\prime}+\Delta \alpha$, $\mathrm{T}_{1}=\mathrm{T}_{1}{ }^{\prime}+\Delta \mathrm{T}_{1}$, and $\mathrm{T}_{2}=\mathrm{T}_{2}{ }^{\prime}+\Delta \mathrm{T}_{2}$ until the convergences were reached. The method of moments was used to determine the $\mathrm{D}_{\mathrm{L}}$ from the $\mathrm{C}$-t profiles obtained at two stations. The $\mathrm{n}^{\text {th }}$ order moment $\left(M_{n}\right)$ of unit impulse response function can be obtained from the corresponding concentration time data as given by Eq. (3):

$$
M_{n}=\frac{\int_{0}^{\infty} t^{n} k(t) d t}{\int_{0}^{\infty} k(t) d t}
$$

Once the mean and variance of the generated as well as the original C-t profiles were available, the Peclet Number, $\mathrm{P}_{\mathrm{e}}$, was calculated as given in Eq. (4):

$$
P_{e}=\frac{2 M_{1}^{2}}{M_{2}-M_{1}^{2}}
$$

The rate of change of moments was applied to compute the $\mathrm{D}_{\mathrm{L}}$ as follows in Eq. (5): 


$$
D_{L}=\frac{\sigma_{x}^{2} u_{m}^{2}}{2 t_{m}}=\frac{M_{2} u_{m}{ }^{2}}{2 M_{1}}
$$

...where $u_{m}$ is mean flow velocity, $M_{1}$ is first moment or mean time $\left(t_{m}\right)$ of C-t profile, and $\sigma_{\mathrm{x}}{ }^{2}$ is the spatial variance that can be represented as the second moment $\left(M_{2}\right)$ of the $\mathrm{C}$-t profile at the sampling point.

\section{Sensitivity Analysis}

The process of determining the change of the response of any water quality model in correspondence to changes in operating conditions, inputs, or parameters may be carried out in a linear or a non-linear manner, according to the operating system of the model. In order to identify just how sensitive the model is to change in a particular parameter, the factor perturbation method may be applied. In determining the level of sensitivity of each parameter, the sensitivity gradient was obtained by means of the partial derivation of the computed model response with respect to each parameter. This concept required the slight variation of one parameter while holding the other model parameters unchanged, and the response of the model was tested with known factors from observed data, which may not portray the real conditions accurately. In this study, the parameters of the HCIS model were varied from their optimal values and their sensitivities have been tested.

\section{Results and Discussion}

\section{Tracer Study and Hydraulic Data}

Fortnight or weekly basis water quality data only are available for most river reaches. Such data would not have sufficed for this study, as the concentration measurements on a minutely or hourly basis were required. In order to demonstrate model capability and optimize model parameters, concentration time profiles from a tracer test presented in [18] were used in this study. The C-t profiles from a slug release of rhodamine WT or B tracer experiment and other hydraulic measurements at three reaches of Spain's Tagus River were obtained from [18]. The river reach downstream of Ermita reservoir along the Tagus has been considered as study reach as presented in Fig. 1. The data sets obtained from the aforementioned study [18] includes i) input tracer concentration $\mathrm{C}_{\mathrm{R}}=18.52 \times 10^{6} \mathrm{mg} / \mathrm{m}^{3}$, ii) mean flow velocity $\mathrm{u}=0.38 \mathrm{~m} / \mathrm{s}$, iii) flow area of $21.06 \mathrm{~m}^{2}$, iv) distance to the first sampling location of $611 \mathrm{~m}$, and v) distance to the second sampling location of $2,451 \mathrm{~m}$.

\section{Estimation of Model Parameters}

The obtained C-t profile was taken under a flow rate of $8.11 \mathrm{~m}^{3} / \mathrm{s}$ at a distance of $611 \mathrm{~m}$ downstream from the tracer injection point, along section one of the Tagus

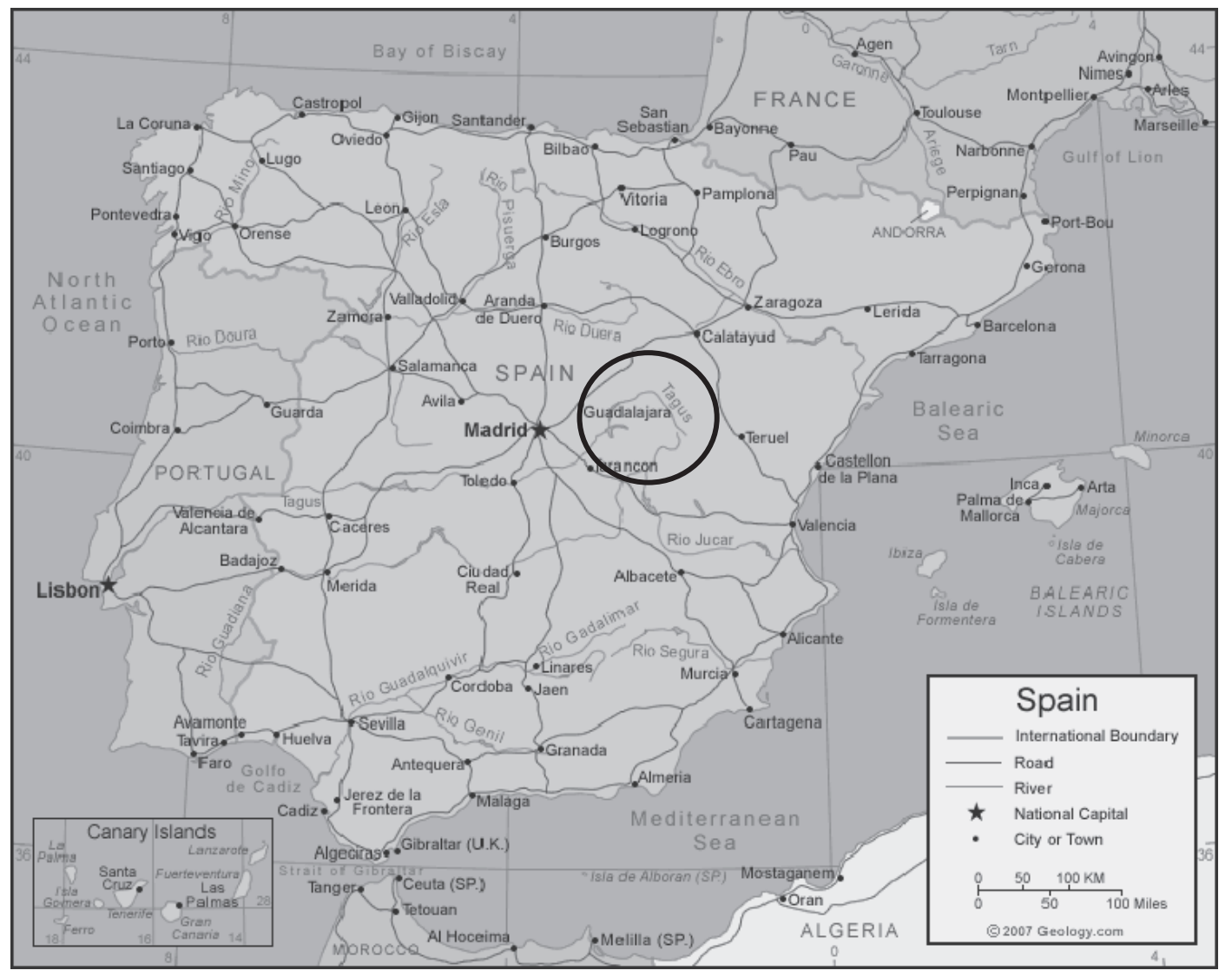

Fig. 1. Map of study area (source: Geology.com). 


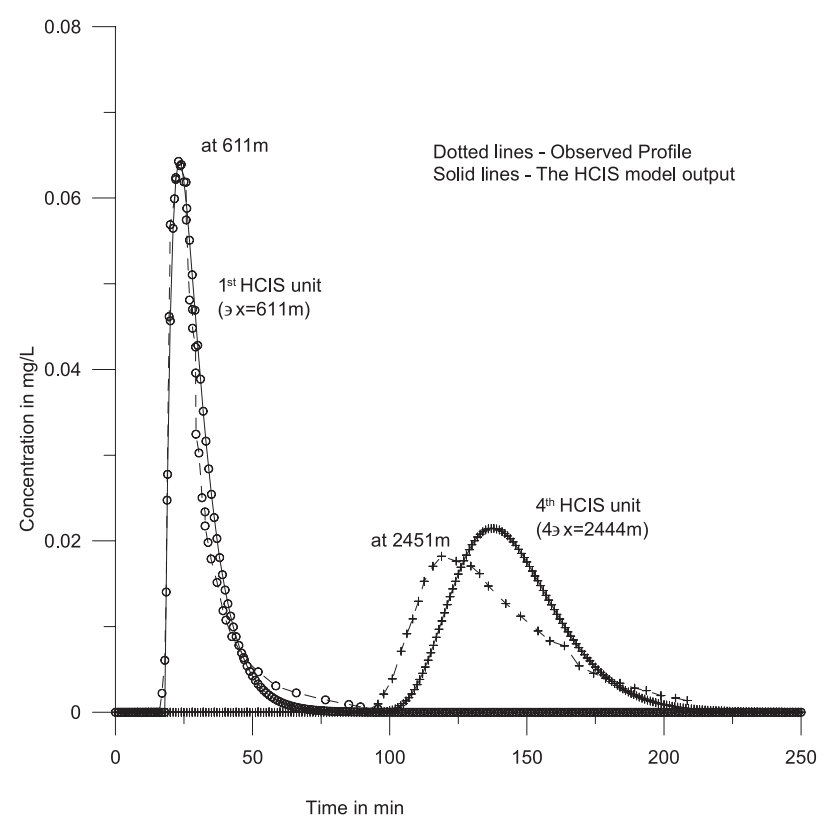

Fig. 2. Comparing the observed profile (obtained from Palancar et al., 2003) with the HCIS model $(\alpha=18 \mathrm{~min}, \mathrm{~T} 1=3.7 \mathrm{~min}$, and $\mathrm{T} 2=8 \mathrm{~min}$ ) output.

River. The area under the observed curve was calculated and used to normalize the data points that produce unit impulse response. Using the least square error optimization method as given in Eq. 2 and its partial derivatives with respect to model parameters, the HCIS model parameters were determined as $\alpha=18 \mathrm{~min}, \mathrm{~T}_{1}=3.7 \mathrm{~min}$, and $\mathrm{T}_{2}=8 \mathrm{~min}$. With the above parameters and time step of 1 minute, the HCIS profile at the first sampling location (at $611 \mathrm{~m}$ ) adequately matched with observed data as shown in Fig. 2.

\section{Generation of Downstream Profile Using Convolution Technique}

The output C-t profile of a downstream location can be obtained by applying the convolution technique. The input parameters for this procedure were the values obtained from the optimization as given in the previous section. The distance at which the output was to be generated would determine the number of hybrid units to consider for the convolution. The parameters were $\alpha=18 \mathrm{~min}$, $\mathrm{T}_{1}=3.7 \mathrm{~min}$, and $\mathrm{T}_{2}=8 \mathrm{~min}$ to generate the response to a unit impulse input from the first hybrid unit. The output of this unit was then taken as the input to the second unit and so on. In order for the same, a discrete kernel of the HCIS model was produced and by successive convolution, the downstream concentration profiles were generated. For a distance of 2,451 $\mathrm{m}$ away from the point of injection of the tracer, approximately four hybrid units with $\Delta \mathrm{x}=611 \mathrm{~m}$ were accommodated, therefore the output concentration time profile of the forth unit was generated. Theoretically the mean of the distribution from the first hybrid unit should be amplified by a factor of four to give the mean of the distribution from the forth hybrid

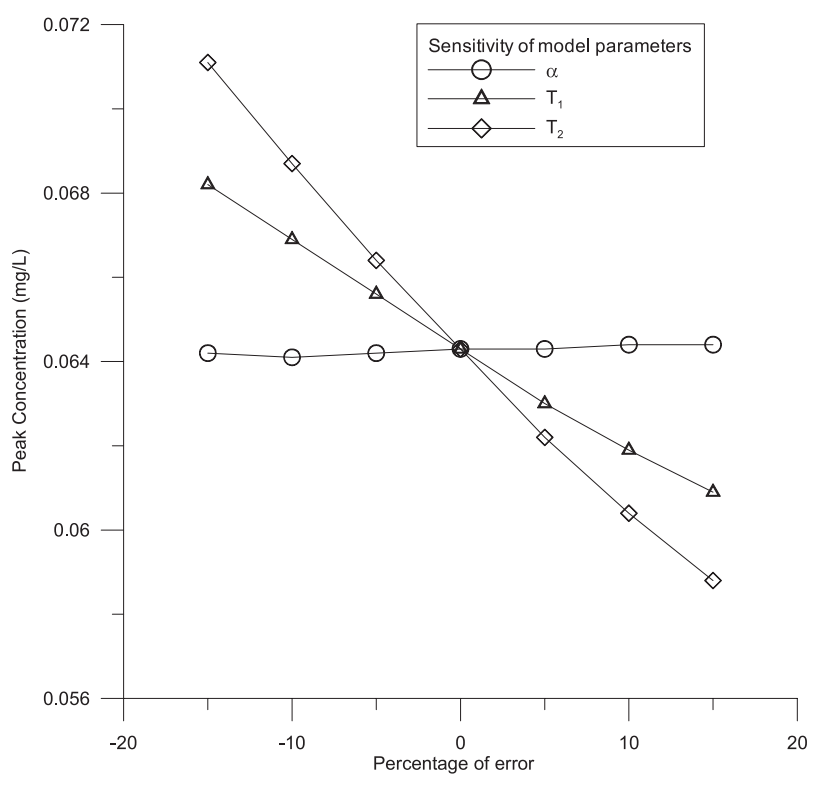

Fig. 3. Sensitivity of model parameters on peak concentration.

unit at a distance of 2,444 $\mathrm{m}$ ( 4 x $611 \mathrm{~m})$. This output was compared with the observed profile from a closer sampling location at a distance of 2,451 $\mathrm{m}$ from injection point as shown in Fig. 2. It can be noted from Fig. 2 that there was a little difference in C-t profiles at the 2,444 m, which could be due to the use of constant parameters in convolution. Due to variations in the channel properties, the model parameters may vary spatially.

\section{Sensitivity of Model Parameters}

As determined from optimization, the optimal values of the HCIS model parameters were $\alpha=18 \mathrm{~min}$, $\mathrm{T}_{1}=3.7 \mathrm{~min}$, and $\mathrm{T}_{2}=8 \mathrm{~min}$ to match with observed profiles. In order to find the sensitivity of the model parameters, the variation of only one parameter while the other parameters remained unchanged may only be applicable over a limited percentage change for the application of the model in real circumstances. The parameters varied by $\pm 5 \%, \pm 10 \%$, and $\pm 15 \%$ from optimal values and further analyses were carried out [19]. From the C-t profiles, it was then possible to acquire the new peak concentrations values in order to plot the sensitivity gradients of each parameter depending on the degree of variation tested as shown in Fig. 3. The sensitivity gradients must also be plotted to show the variation of the Peclet number with a change in parameters shown in Fig. 4. When taking the first time parameter, $\alpha$, to be $85 \%$ of its optimal value, the concentration profile remains zero for an elapsed time of approximately $15 \mathrm{~min}$. On the other hand, an increase in $\alpha$ by $15 \%$ of its optimal value produced a "lag" time of approximately $20 \mathrm{~min}$. Since $\alpha$ governs the pure advection which occurs in the plug flow zone of the HCIS model, the Peclet number was affected significantly and the proportion of the advective process is directly related to the Peclet number.

The change in $T_{1}$ essentially affects the amount of dispersion that occurs in the first well-mixed cell. The 


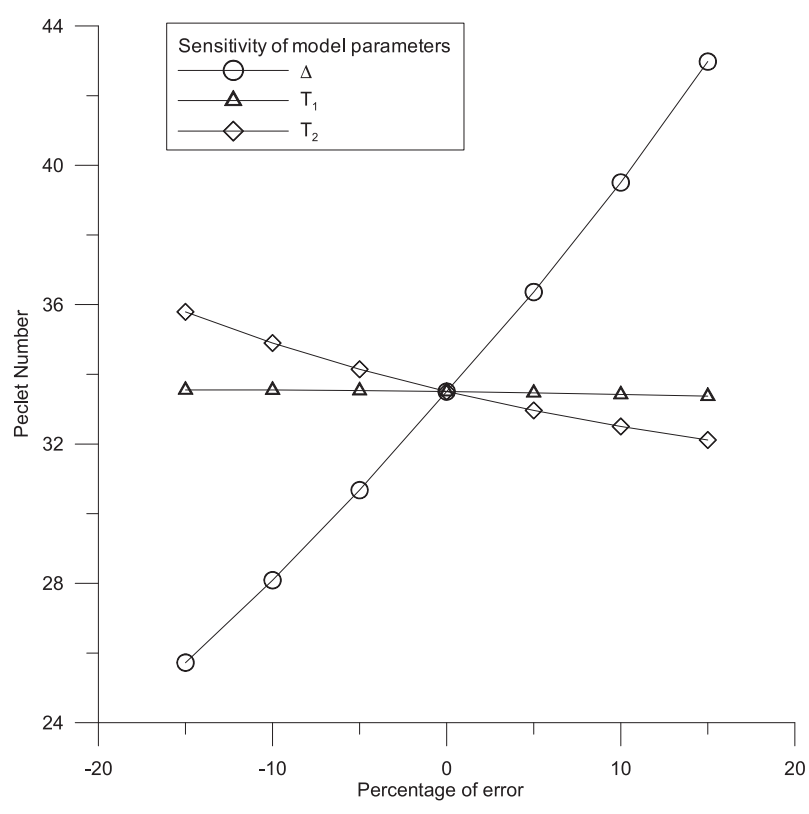

Fig. 4. Sensitivity of model parameters on Peclet number.

value of $\mathrm{T}_{1}$ was first decreased by 5,10 , and $15 \%$ from optimal value, and respective peak concentrations are estimated and presented in Fig. 3. As can be noted from Fig. 3, the peak concentration increases from $0.064 \mathrm{mg} / 1$ at $\mathrm{T}_{1}=3.7 \mathrm{~min}$ to $0.068 \mathrm{mg} / \mathrm{l}$ when the parameter was taken as $85 \%$ of its optimal value. Similarly, the value of $\mathrm{T}_{1}$ was increased up to a maximum of $15 \%$ of its optimal value, which resulted in the corresponding peak concentration decreasing to $0.06 \mathrm{mg} / \mathrm{l}$. Throughout the investigation on the sensitivity of $T_{1}$, the alterations to the optimum value of the parameter caused the Peclet number to vary only slightly, which can be seen in Fig. 4. The effect of $\mathrm{T}_{1}$ on the Peclet Number was seemingly negligible in comparison to the effect which changes in $\alpha$ had on this ratio. Keeping $\mathrm{T}_{2}$ at the optimal value of $8 \mathrm{~min}$, the peak concentration from the HCIS model was $0.064 \mathrm{mg} / \mathrm{l}$. When $\mathrm{T}_{2}$ was decreased by $15 \%$, the peak concentration then increased to $0.071 \mathrm{mg} / \mathrm{l}$, indicating that the proportion of dispersive transport has been decreased. Conversely, a 15\% increase

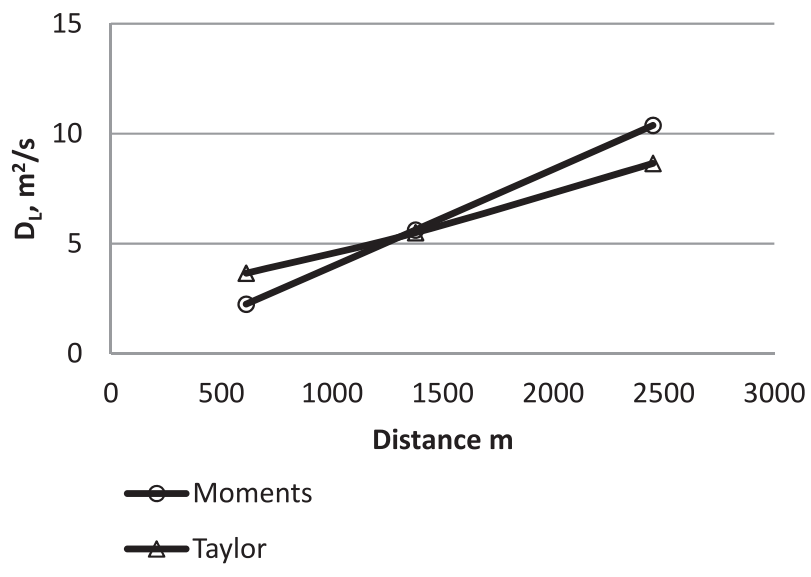

Fig. 5. Variation of dispersion co-efficient along the river reach. in $\mathrm{T}_{2}$ increases the dispersion and decreases the peak concentration to $0.059 \mathrm{mg} / \mathrm{l}$ as shown in Fig. 3. It can be observed from Fig. 4 that the increase in $\mathrm{T}_{2}$ resulted in a decrease in of Peclet number. A similar trend was noted to that of $\mathrm{T}_{1}$, but at a less noticeable level. The Peclet number is 32.11 and increases to 35.79 for a respective increase and decrease of $\mathrm{T}_{2}$ by $15 \%$.

\section{Method of Moments for Dispersion Coefficient}

The $\mathrm{D}_{\mathrm{L}}$ was determined by Eqs. (3) and (5) as $2.25 \mathrm{~m}^{2} / \mathrm{s}$ and $10.38 \mathrm{~m}^{2} / \mathrm{s}$ at first and second sampling points from the observed C-t profiles. At the first and second sampling points, it was calculated in [18] using Taylor's equation as $3.66 \mathrm{~m}^{2} / \mathrm{s}$ and $8.65 \mathrm{~m}^{2} / \mathrm{s}$ respectively. The $\mathrm{D}_{\mathrm{L}}$ values were calculated using the method of moments along the river reach as presented in Fig. 5, which was comparable with the same using Taylor's equation as presented in [18].

\section{Conclusion}

The sensitivity of the model response was analyzed with regard to perturbations in the three time parameters. In the HCIS model the unequal residence times of wellmixed $T_{1}$ and $T_{2}$ cells are interchangeable. The conclusion to this investigation is that $T_{2}$ has the greatest effect on the overall model response to a unit impulse input. Small errors in $\mathrm{T}_{2}$ have a considerable effect on the dispersive processes within a hybrid unit, therefore relating to both the peak concentration as well as the Peclet number. The peak concentration is most sensitive to changes in $T_{2}$ and least sensitive to changes in $\alpha$, although the time to peak will vary. The Peclet number is considerably sensitive to changes in $T_{2}$, although changes in $\alpha$ cause a greater disturbance in this regard.

The Convolution technique applied to generate the HCIS model response at a downstream unit yielded acceptable results with errors, which can be justified and rectified. Thus there is a scope to improve the HCIS model with spatially varying model parameters. The profile generated from the convolution stage of this investigation was used to determine the first and second moments of the C-t distribution. It can be concluded that the method of moments may be incorporated in determining the $\mathrm{D}_{\mathrm{L}}$ in the application of the HCIS model as well as other water quality models to practical field situations.

The performance of further investigation will aid in the elimination of uncertainties brought about by the conventional method of determining $\mathrm{D}_{\mathrm{L}}$, since physical channel properties are hardly ever constant along any river reach. Using the change of moment method has become a favourable approach when determining the $\mathrm{D}_{\mathrm{L}}$.

\section{Acknowledgements}

The authors acknowledge all the support by the Water Research Commission in South Africa for this publication. 


\section{References}

1. NKWONTA O.I., OCHIENG G.M. Water Pollution in Soshanguve Environs of South Africa. World Academy of Science, Engineering and Technology. 56, 499, 2009.

2. OWA F.D. Water Pollution: Sources, Effects, Control and Management. Mediterranean Journal of Social Sciences. 4 (8), 65, 2013.

3. SINCLAIR K.M. Characterising the Relationship between Water Quality and Water Quantity. Final Report, Department of Sustainability, Environment, Water, Population and Communities, Australia, 2013

4. SWANEPOEL C.L. An assessment of the health related microbial water quality of the Blesbok Spruit. M.Tech Dissertation, University of Johennesburg, 2009.

5. VAN DER MERWE-BOTHA M. Water quality: A vital dimension of water security. Development Planning Division. Working Paper Series No.14, DBSA: Midrand, 2009.

6. TSAKIRIS G. ALEXAKIS D. Water quality models: An overview. European Water. 37, 33, 2012.

7. MARUSIC G. A study on the mathematical modeling of water quality in "river-type" aquatic systems. WSEAS transactions on fluid mechanics. 8 (2), 80, 2013.

8. GHOSH N.C., MISHRA G.C., MUTHUKRISHNAVELLAISAMY K. Hybrid-cells-inseries model for solute transport in streams and relation of its parameters with bulk flow characteristics. J. Hydraul. Eng., ASCE, 134 (4), 497, 2008.

9. MUTHUKRISHNAVELLAISAMY K., MISHRA G.C., KANSAL M.L. GHOSH N.C. Estimation of stream water quality parameter using regime channel theory. Environ. Geol. 57 (4), 899, 2009.
10. MUTHUKRISHNAVELLAISAMY K., MISHRA G.C., GHOSH N.C., KANSAL M.L. A semi analytical solution for non-equilibrium sorption of pollutants transport in streams. J. of Environ. Eng. ASCE. 137 (11), 1066, 2011.

11. MARTIN J.E., CARR M.L., GARCIA M.H. Riverine Transport, Mixing and Dispersion. Ed. FERNANDO H.J.S., Handbook of Environmental Fluid Dynamics. 2, CRC Press, New York, 2013.

12. BANKS R.B. A Mixing Cell Model for Longitudinal Dispersion in Open Channel. Water Resour. Res., 10 (2), 357, 1974.

13. BEER T., YOUNG P.C. Longitudinal Dispersion in Natural Streams. J. Environ. Eng. Div. ASCE, 109 (5), 1049, 1983.

14. GHOSH N.C., MISHRA G.C. OJHA C.S.P. A hybrid-cellsin-series model for solute transport in a river. J. Environ. Eng. Div. ASCE. 130 (10), 1198, 2004.

15. DENG Z.-Q., JUNG H.-S. Variable residence time based model for solute transport in streams. Water Resourc. Res. 45, W03415, 2009.

16. MUTHUKRISHNAVELLAISAMY K., GHOSH. N.C., MISHRA G.C., KANSAL M.L. Hybrid Model Development for the Decaying Pollutant Transport in Streams. International Journal of Environment and Waste Management. 12 (2), 130, 2013.

17. NAIDOO R. Estimation of Water Quality Parameters. BSc Dissertation, University of KwaZulu-Natal, Durban. 70, 2010.

18. PALANCAR M.C., ARAGÓN J.M., SÁNCHEZ F., GIL R. The Determination of Longitudinal Dispersion Coefficients in Rivers. Water Environment Research. 75 (4), 324, 2003.

19. NAIDOO N. Sensitivity analysis of the Hybrid Cells in series water quality model. BSc Dissertation, Univerity of KwaZulu-Natal, Durban, 68, 2011. 